\title{
Improving Marketing Competitiveness And Innovative Strengthening Through SMEs
}

Aristides R. Baraya, Southeastern Louisiana University, USA Lizette Brenes Bonilla, Universidad Estatal a Distancia, Costa Rica Michael Craig Budden, Southeastern Louisiana University, USA

\begin{abstract}
Taiwan has been known for its effective policies and positive economic impact on the development of SMEs in that country. Recognizing the importance of the role that government can play in the development of SMEs, Costa Rica has started developing policies to strengthen its SMEs. Both countries rely heavily on SMEs to contribute to their productive capacities. The parallel between Taiwan and Costa Rica presented indicates that the success Taiwan has had in strengthening SMEs may be useful for Costa Rica as it moves to the initial stages of strengthening SMEs.
\end{abstract}

\section{INTRODUCTION}

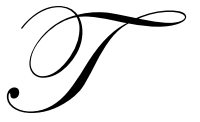

he need to improve competitiveness of SMEs in Costa Rica is discussed by Baraya, Budden and Brenes (2006). Baraya, Budden and Brenes indicated two primary issues to improve competitiveness concern 1) enterprise financing and 2) providing managerial support to the owner/managers of SMEs. In the interest of learning from better practices, especially from countries which have been successful in the strengthening of their SMEs, Taiwan's successful experiences should not be lost on Costa Rica. In a United Nations report on the effect of governmental policies on industrial competitiveness, Taiwan was recognized (United Nations Conference on Trade and Development, 2004) as a positive example of SME development policies.

Taiwan has been recognized as a role model because of its amazing economic achievements, currently holding seventeenth place among the world's economies. Taiwan ranks fifteenth among the world's exporters and ranks third in foreign currency reserves (Economist.com, 2006). These accomplishments become even more impressive once the relative importance of SMEs in the country's economy and the strategies developed to strengthen SMEs are considered. Taiwan's SME strategy differentiates Taiwan from many other countries whose economic development strategies ostensibly are directed at developing larger enterprises, like Japan and Korea.

Drawing parallels between Costa Rica and Taiwan allows identifying similarities and differences, which inspire various useful lessons for strengthening the development of SMEs in Costa Rica. For example, both Taiwan and Costa Rica are located geographically in strategic areas of the world. Taiwan (the Republic of China) is positioned on the Pacific Rim. It is located close to the People's Republic of China, Japan, Philippines and South Korea - all major economic powers and exporters of a variety of goods. Costa Rica is in the center of the Americas, conveniently close to the United States, Canada, Mexico, Panama, the Caribbean and South America. Again, both countries are situated near major economic influences on the world's economies.

Both countries have relatively small landmasses. Taiwan covers only $35980 \mathrm{Km}^{2}$ while Costa Rica, being larger than Taiwan covers some $51100 \mathrm{Km}^{2}$. The small land sizes of the countries dictate that resource utilizations be efficient if strategic competencies are to pay off in an improved economic impact.

As is true in other advanced economies, service providers play important roles in the economies of both Costa Rica and Taiwan. Both large and small firms can be found among service providers. However, service providers are primarily SMEs. The service sector has grown in both countries and represents a significant share of 
GDP. Service providers are responsible for a $67.6 \%$ share of the Taiwanese economy, while in Costa Rica; service providers represent more than $60 \%$ of that country's GDP (Leitón, 2005).

Education and the central role it can play in moving people and economies forward is recognized in both countries. In Taiwan and Costa Rica, education is expected, encouraged, and legally required. Costa Rica, perhaps uniquely, disbanded its military shortly after World War II with the express purpose of redirecting government investments into social and education initiatives. The resulting emphasis in both countries on the importance of an educated populace can be seen in literacy statistics. In Taiwan, the literacy rate is better than $96.9 \%$ while in Costa Rica, it is $95.8 \%$.

Finally, SMEs in both countries make substantial contributions to their respective economies. In Taiwan, SMEs represent $97.8 \%$ of enterprises, exceeding a million enterprises; employing $78 \%$ of the work force (SMEA, 2000). In Costa Rica, 51.42\% of the private workforce can be found in SMEs (Caja Costarricense del Seguro Social, 2006). Regarding this aspect, Taiwan is different from other successful Asian countries, like Japan, much of whose growth can be traced to the development and expansion of large enterprises.

Both Taiwan and Costa Rica have turned to specialized legislation in order to promote the development of SMEs, even though Taiwan started to promote such legislations ten years before Costa Rica. Legislation provides direction and funding. Legislation provides a sense of urgency and importance to the effort. In both countries, legislation has been established to further the cause and impact of SMEs. It is through this device that Taiwan improved its core business sector, and it is through such an effort that Costa Rica hopes to bolster its efforts.

There are some parallels and some differences of interest between the countries. For example, Taiwan's population is five times that of Costa Rica, as is its Gross Domestic Product per capita. Two key strategies that separate these countries are: investment on education and investment on research, innovation and development. Taiwan invests $16.6 \%$ of its GIP in education and $2.2 \%$ of GIP in research, innovation and development. On the other hand, Costa Rica invests only $6 \%$ and $0.39 \%$ in these areas, respectively.

The following points allow for an improved understanding of the lessons offered by the parallels noted and provide a platform for the strengthening of Costa Rican SMEs.

The points presented:

1. Policies and strategic planning can provide a framework for the strengthening of SMEs.

2. The importance of effective coordination among the government, industry and education in order to advance SMEs.

3. Innovation and synergy are vital to improve the competitiveness of SMEs.

\section{LESSONS LEARNED}

\section{First Lesson: National strategic plan and strategic policies on SMEs.}

Strategic clarity of Taiwan's plan can be confirmed in its three strategic objectives: To strengthen Taiwan's international competitiveness, to ensure its number one position in Asia and to be among the top three countries (economies) worldwide.

Among Taiwan's goals that show strategic clarity are the following:

- $\quad$ To expand both its number of products and its technologies in order to move its position to $15^{\text {th }}$ among those considered the best in the world

- $\quad$ To double the number of foreign visitors coming to Taiwan

- $\quad$ To increase to 3 per cent of GNP its expenditure on research and development

- $\quad$ To reduce the mean unemployment rate to less than $4 \%$

- $\quad$ To increase its economic growth to over 5 percent annually 
- To increase the number of citizens with broad band Internet access to over six million

The plan is not an intention guide but one backed with resources. The ROC government plans to assign NT\$500 thousand millions (US\$14.7 billion) in the next five years to carry out its "Ten New Main Development Projects," which include innovative goals such as the desire to cultivate first class talent and to strengthen innovative research and development; to invest in knowledge based industries; to develop cultural creativity as well as to complete a wide distribution net; to raise international competitiveness and to ensure a convenient and sustainable living environment.

Taiwan developed policies and strategies towards the strengthening of SMEs, by creating, for example, a credit security fund for SMEs that allows beneficiaries to obtain the capital necessary for their projects using a guarantee provided by the government fund. Decisions are made by a board with representation from different productive sectors. This fund is complemented with a fiscal credit equivalent up to a $20 \%$ tax credit so as to stimulate investments in SMEs. Another example of an effective policy is a fund for research and development as part of a national strategy of incubation that allows developing patents with previous research processes, during which entrepreneurs can become involved in the process along with scientists (UNCTAD, 2004). These policies are driving innovation and development and creating success stories among SMEs that can be duplicated elsewhere. Intention must be backed with resources to be successful and in Taiwan, the country's leaders are "putting their money where their mouths are."

\section{Second Lesson: Effective coordination between academy, government and industry}

In the ROC, around eighty per cent of incubation centers financed by the government have been established by domestic universities. As Her (2003) emphasizes, incubators not only serve to create and expand high technology companies and advance local development, but are mechanisms to facilitate cooperation between government, intellectuals and industry. Such cooperation can lead to effective alliances.

Coordination of effort has allowed a countrywide web formation of over twenty SME support centers. There is also an "instant solutions centre" which supported by a web of voluntary advisers called "Honorary Volunteer Directors/Advisers," offers free advice to entrepreneurs to overcome technical or work-related problems. This solution center is credited with advancing managerial understanding, efficiency and productivity.

Under the initiative of the Instituto Tecnologico de Costa Rica, that country has its first experience with an entrepreneurial incubator. This incubator impels new companies that may rise from university classrooms, passing through various stages of development and subsequent monitoring performed by the Incubator. The Institute has been in existence for 35 years. The incubator has successfully assisted out, more than 100 new businesses. This is a beginning and there is hope that additional incubators will come on-line to grow businesses as successfully as the ROC has done with its SMEs.

(More information http://www.cietec.org/)

\section{Third lesson: innovation and synergy}

Taiwan has made a strategic turn in production in the last fifty years. Enriquez (2004) states that Taiwan's production evolved from heavy industry to light industry and from manufacturing intensively based on labor to manufacturing development intensively based on technology. According to Forbes magazine (2005) "Best 100 Asia's SMEs," Taiwan's new productive strategy has a growing competitiveness in continental China, Japan and Korea.

Tanzer (2004) considers innovation to be the primary strategy for SMEs to follow in the face of adversity. If not followed, it is believed they will be forced to relocate to places that permit lower costs. Taiwanese SMEs count on solution incubators and on their support to encourage innovation and to register patents. 
Synergy started to germinate in 2001 when a venture capital enterprise was created in Taiwan in order to generate resources to make incubators sustainable. The project intended beneficiaries to contribute part of their profits for the support of new initiatives and "to transform innovation into money earning models which in turn will create more successful stories" (Her, 2003).

From another point of view, international acknowledgment of results in Taiwan encourages larger firms to consider it an environment for innovation not just for SMEs, but for all. For example, Intel established an "Innovation Centre" in Taiwan in 2003, the first one to be established by an American company in the region. The objective of working together with the government, academy and entrepreneurs in order to turn the country into "an innovation regional centre for digital convergence" is at the center of the effort (Profile Taiwan, 2006).

\section{CONCLUSIONS AND RECOMMENDATIONS}

Costa Rica and Taiwan are strategically located small countries. Each has easy access to large markets. However; their economies differ broadly even though production, in both countries is largely the result of the efforts of small and medium size enterprises. Costa Rica can take advantage of successful strategies and policies pioneered by Taiwan to strengthen its SMEs and their competitiveness including:

- $\quad$ Policies and effective national strategic planning based on known SMEs' needs. Policies that include effective guarantee funds, management advisement and fiscal benefits for investments in SMEs are needed.

- $\quad$ Policies need to encourage coordination between government, academics and industry.

- Innovation and synergy must stop being possibilities and become survival necessities for SMEs. There is a need for alliances and innovation efforts. Incubator environments where existing enterprises can seek development support are needed.

- $\quad$ Efforts toward innovation will generate a favorable business environment and encourage direct foreign investment, which in turn will drive additional development.

Due to scarce Costa Rican experience with SME-oriented policies, research aimed at understanding SME needs and successes should follow. There is still much to do to encourage the growth and development of SMEs in Costa Rica. A better understanding of SMEs' needs, characteristics and behavior is needed. Through a coordinated, supported environment which encourages entrepreneurial spirit, drive and risk-taking, Costa Rica can advance its SMEs. Costa Rica's educational resources can be brought to bear to improve the success rate of SMEs, to further the positive impact SMEs are having on the economy and welfare of Costa Rica's citizens, and advance the nation as its people desire.

\section{BIBLIOGRAPHY AND SOURCES}

1. Baraya, A. R., Budden, M. C. and Bonilla, L. B. (2006). Strategic role, challenges and opportunities for small and medium enterprises facing DR-CAFTA: The Case of Costa Rica. Journal of College Teaching and Learning.

2. Caja Costarricense del Seguro Social (2006). Estadísticas de la Dirección Actuarial. Costa Rica.

3. CONARE (2005) Estado de la Nación: XI Informe. Costa Rica.

4. Enriquez, J. (2004) Mientras el futuro te alcanza. Círculo cultural Azteca. México.

5. $\quad$ Forbes Magazine (2005, November) Ranking the "Best 100 Asia's SMEs."

6. Her, K. (2003) Listo e inteligente. Oxford Press.

7. Leitón, P. "Costa Rica se transforma en una economía de servicios" Recuperado en http://www.nacion.com/ln_ee/2005/octubre/17/economia0.html,18 de marzo 2006.

8. Profile Taiwan. The Economist. Recuperado en http://www.economist.com/countries /Taiwan/ profile.cfm?folder=Profile-FactSheet 11 de marzo 2006.

9. Small \& Medium Enterprise Administration. (2003) Small and Medium Enterprise Incubation Centers in Taiwan, Ministry of Economic Affairs. Taiwan.

10. SMEA (2000). White Paper on Small and Medium Enterprises in Taiwan. Ministry of Economic Affairs, ROC. 
11. SMEA Taiwan. "Emphasizing Human Resource development” Recuperado en: http://www.moeasmea.gov.tw/Eng/startUp/d03.asp 21 de enero 2006.

12. Taiwan business (2002) World Trade Press.

13. Taiwan positive example of SME development policy. UNCTAD. Recuperado en http://investintaiwan.nat.gov.tw/en/news/200406/2004063009.html , 25 de febrero 2006.

14. Tanzer, A. (2004) "Made in Taiwan" Forbes. Recuperado en http://www.forbes.com/global/2001/0402/024.html 10 de diciembre 2005.

15. The case of Taiwán. ROC. Recuperado en http://www.fsf.se/Patterns/CH10-T 1.DOC.pdf 25 de febrero 2006.

16. United Nations Conference on Trade and Development (2004). UNCTAD: Report on the role of government policy on industrial competitiveness.

\section{NOTES}


NOTES 